\title{
Dournal of Naval Architecture and Marine Engineering \\ MODELING OF ANNULAR PREDIFFUSER FOR MARINE GAS TURBINE COMBUSTOR USING CFD - A STUDY ON THE EFFECT OF STRUT CONFIGURATION
}

\author{
A. Sheeba ${ }^{1}$ and V. Ganesan ${ }^{2}$ \\ ${ }^{1}$ M. Tech Student, Indian Institute of Technology Madras, Chennai - 600 036, India, Email: \\ sheeba_jameel@yahoo.co.in \\ ${ }^{2}$ Professor, Internal Combustion Engine Laboratory, Department of Mechanical Engineering, Indian Institute of \\ Technology Madras, Chennai - 600 036, India, Email : vganesan@iitm.ac.in
}

\begin{abstract}
This paper presents the numerical and experimental investigation of a straight core annular diffuser normally used in marine gas turbine combustor. The flow in the annular diffuser has been simulated by solving the equations for conservation of mass and momentum. For turbulence modeling the standard $k-\varepsilon$ model is employed and the predicted results have been validated with experiments. A five-hole probe and a single normal hot wire anemometer were used to measure mean and fluctuating components of velocity. The comparison of the experimental and predicted mean velocity values in radial direction, at different axial locations of annular diffuser is presented and discussed. Flow development in the annular diffuser with different strut geometries has been analyzed. The discussion is focused on the distortion of the flow produced by the strut configuration.
\end{abstract}

Keywords: Annular Diffuser, Struts, Recirculation Region

\section{NOMENCLATURE}

$C_{p} \quad$ Pressure recovery coefficient

$C_{p i} \quad$ Ideal Pressure recovery coefficient

$K \quad$ Pressure loss coefficient

$P i \quad$ Static pressure at inlet to diffuser, $\mathrm{Pa}$

Pst Static pressure at any section, $\mathrm{Pa}$

$\eta \quad$ Effectiveness

$U i \quad$ Mean velocity at inlet, $\mathrm{m} / \mathrm{s}$

$X \quad$ Longitudinal distance, $\mathrm{m}$

\section{Introduction}

Efficiency of a gas turbine is largely dependent on its turbo machinery components. Diffusers of annular type are used in turbo machines because of the necessity of a fluid stream to flow over and around a central shaft and bearing. A pre-diffuser is employed in a gas turbine between compressor and combustion chamber, to reduce the velocity level of the stream to avoid blow out of the flame. The air has to be decelerated to initiate and sustain the combustion process in the primary zone of the combustor.

The diffuser of a gas turbine often features structural element called struts, which extend radially from the inner to the outer annulus wall, act as bluff bodies and consequently cause unsteady wakes. Lohmann et al (1979) experimentally determined the performance of a series of diffusers of various lengths, area ratios and cant angles over a range of inlet flow swirl angles between axial and 48 degrees. Ganesan (1980) numerically investigated the flow and boundary layer development in straight core annular diffusers using finite difference method and marching integration technique. Turner and Roach (1985) investigated the secondary flows generated by the interaction between the strut crosssection and end wall boundary layers. Shyy (1985) conducted a series of flow calculations for a model

1813-8535 @ 2005 ANAME Publication. All rights reserved. 
annular dump diffuser. The influences of the numerical schemes and their interaction with grid distribution are investigated. Hobson (1990) investigated experimentally the unsteady behavior of flow in an eccentric annular diffuser. Fric et al (1995) conducted scale-model tests and suggests that the effect of tapered struts is to shift vortex shedding frequency and reduce its amplitude. Shuja and Habib (1995) validated a numerical procedure for the calculation of turbulent separated flow and heat transfer characteristics in axisymmetric expanding duct, with emphasis on the annular diffuser geometry. Xia et al (1999) conducted numerical and experimental investigation of turbulent flows occurring in a $180^{\circ}$ bend annular diffuser with an aperture in front of the bend. Stefano Ubertini and Umberto Desideri (2000) have presented three-dimensional characterization of flow through a scaled down model of a gas turbine diffuser. The aim of their research was to determine the performance of annular diffuser and predict the effect of struts and strut position in the annular diffuser geometry. Stefano Ubertini and Umberto Desideri (2000) presented the performance of an annular diffuser with and without struts. Thus, it is seen that there is a considerable interest in the flow behavior in presence of struts for flow through diffusers.

Fluid flow processes can be analyzed both experimentally and numerically. Experimental methods can greatly help in understanding the flow behavior and also can help in assessing available theoretical predictions. With the availability of fast digital computers, it is now possible to solve the governing equations of turbulent flows using turbulence modeling principles to give reasonably accurate results at much shorter time. This will enable the design optimization by which the number of costly experiments can be reduced. In the present investigation, both experimental and numerical simulations have been carried out to predict the flow characteristics inside an annular diffuser and analyze the effects of struts configuration.

Flow has been simulated using FLUENT code. The predictions are made using the standard $\mathrm{k}-\varepsilon$ model and the predicted results have been validated with experiments.

\section{Computational Details}

A full-length three-dimensional model of an annular diffuser has been modeled using GAMBIT, preprocessor. Figure 1 shows the modeled geometry of the annular diffuser with grid. The schematic view of the annular diffuser is shown in Figure 2. The model contains eight struts of $8 \mathrm{~mm}$ diameter. The strut region has been meshed using unstructured grid (tetrahedral) and the remaining regions with structured mesh. Different grid densities have been tried and a grid independence test has been performed. The predicted velocity profiles for various grids have been compared. It has been observed that 490047 elements grid is suitable both from the point of view of accuracy and computational time.

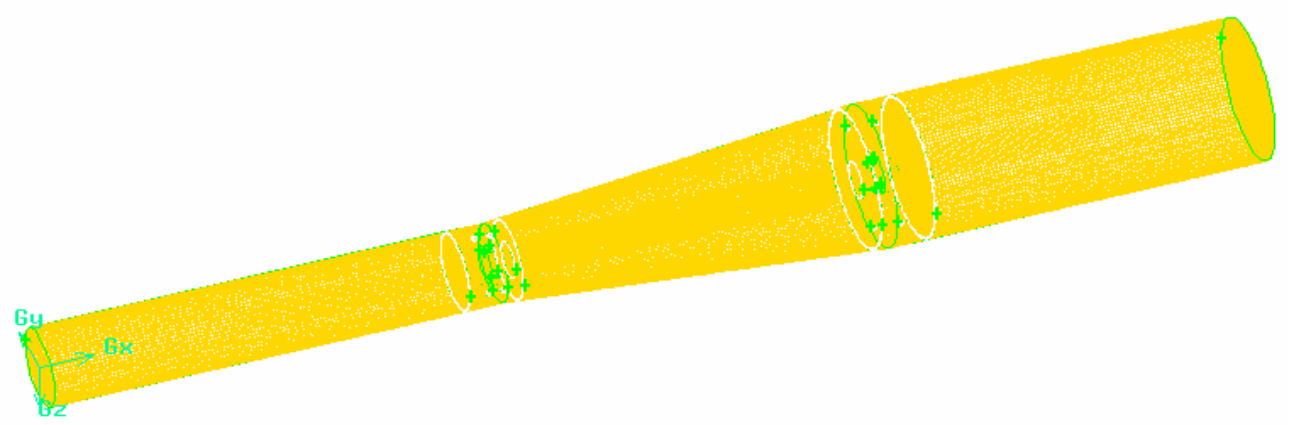

Figure 1: Modeled geometry of the annular diffuser with grid.

\subsection{Boundary conditions}

Boundary conditions are incorporated to the meshed model in the GAMBIT and exported to FLUENT, solver and post processor. The present problem has three boundaries. They are inlet, outlet and wall boundary. 
At the inlet boundary, a fixed velocity was specified. The code required the magnitude of the velocity normal to the boundary. The inlet turbulent intensity level is taken as 6 percent and the hydraulic diameter at the inlet is given as $0.057 \mathrm{~m}$

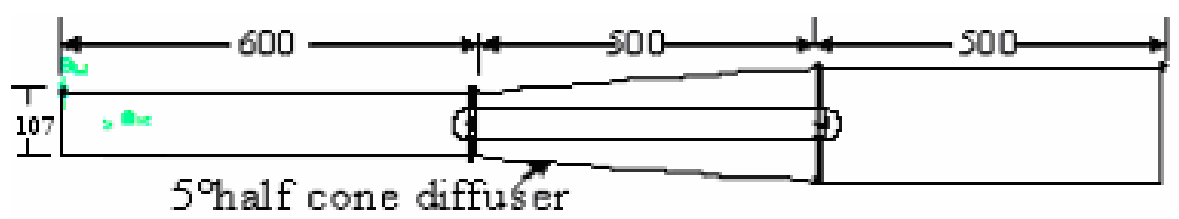

Figure 2: Schematic view of annular diffuser

An outflow boundary condition is specified at the outlet. Pressure and velocity information are not required at the outlet. Data at exit plane is extrapolated from the interior. Mass balance correction is applied at the boundary.

Wall boundary condition is used to bound fluid and solid zones. In the present case walls are assumed to be adiabatic with no slip condition. Reynold's number of the flow becomes very low and turbulent fluctuations are damped considerably, near the walls. The laminar viscosity starts to play a significant role. The shear stress between the fluid and the wall are computed based on the flow details in the local flow field.

The following assumptions pertaining to the flow have been made in the present study:

- Flow is steady, incompressible and turbulent

- Buoyancy effects are neglected

- Conjugate heat transfer and radiation effects are neglected

The flow in the annular diffuser has been simulated by solving the equations for conservation of mass and momentum. Finite volume technique based method has been used to convert the governing equations of flow to algebraic equations that can be solved numerically. The pressure-velocity coupling has been achieved by SIMPLE algorithm. Turbulence in the flow has been modeled using the standard $k$ - $\varepsilon$ model. The eddy viscosity and conductivity are expressed in terms of two turbulence variables, the turbulence kinetic energy $k$ and its rate of dissipation $\varepsilon$.

\subsection{Governing Equations}

The time-averaged governing equations for fluid flow in the Cartesian tensor form are presented below

\section{Continuity Equation}

$$
\frac{\partial}{\partial X_{i}}\left(\rho u_{i}\right)=0
$$

\section{Momentum Equation}

$$
\frac{\partial}{\partial X_{j}}\left(\rho u_{i} u_{j}\right)=-\frac{\partial p}{\partial X_{i}}+\frac{\partial}{\partial X_{j}}\left[\mu\left(\frac{\partial u_{i}}{\partial X_{j}}+\frac{\partial u_{j}}{\partial X_{i}}-\frac{2}{3} \delta_{i j} \frac{\partial u_{i}}{\partial X_{i}}\right)\right]+\frac{\partial}{\partial X_{j}}\left(-\rho \overline{u_{i}^{\prime} u_{j}^{\prime}}\right)+F_{i}
$$

where $p$ is the static pressure, $\mu$ the molecular viscosity, $\delta_{i j}$ is kronecker-delta function and $F_{i}$ is the external body force that arises from interaction with the dispersed phase in the $i$ direction .The second term in the right hand side represents the stress tensor denoted by $\tau_{i j}$. The third term in the right hand side of the above equation represents Reynolds stresses and these are modeled using Boussinesq hypothesis. According to this hypothesis the Reynolds stresses are related to the mean velocity gradients by 


$$
-\rho \overline{u_{i}^{\prime} u_{j}^{\prime}}=\mu_{t}\left(\frac{\partial u_{i}}{\partial X_{j}}+\frac{\partial u_{j}}{\partial X_{i}}\right)-\frac{2}{3}\left(\rho k+\mu_{t} \frac{\partial u_{i}}{\partial X_{i}}\right) \delta_{i j}
$$

where $k$ is the turbulent kinetic energy and $\mu_{t}$ is turbulent viscosity whose computational method depends on the type of turbulence model used.

\subsection{Turbulence Modeling}

The standard $k$ - $\varepsilon$ model is a semi-empirical model based on model transport equations for the turbulence kinetic energy $(k)$ and its dissipation rate $(\varepsilon)$. The model transport equation for $\mathrm{k}$ is derived from the exact equation, while the model transport equation for $\varepsilon$ was obtained using physical reasoning and bears little resemblance to its mathematically exact counterpart.

In the present study the two equation $k-\varepsilon$ turbulence model, which is based on the generalized Boussinesq eddy viscosity concept is employed. This model uses two partial differential equations to estimate the turbulent viscosity $\mu_{t}$ that may be related to the turbulent kinetic energy (k) and its dissipation rate $(\varepsilon)$ by dimensional analysis.

\section{Parametric Studies}

Inlet blockage is a major factor, which affects the performance of the diffuser. The shape of the struts and the position of struts influence the flow characteristics. In order to study the influence of geometrical parameters viz shape of the struts with a stream lined centre body as shown in Figures 3 and 4 has been considered, which affect the flow characteristics in an annular diffuser. Three different geometries have been simulated, analyzed and discussed. The details of different geometries used for the simulation are given below.

$>$ Case A: Annular diffuser with stream lined centre body with circular struts (Figure 3)

$>$ Case B: Annular diffuser with stream lined centre body without struts

> Case C: Annular diffuser with stream lined centre body with aerofoil shaped struts Shape of the aerofoil shape is shown in Figure 4.

Experiments have been conducted in Case A configuration for the validation of the predicted results.

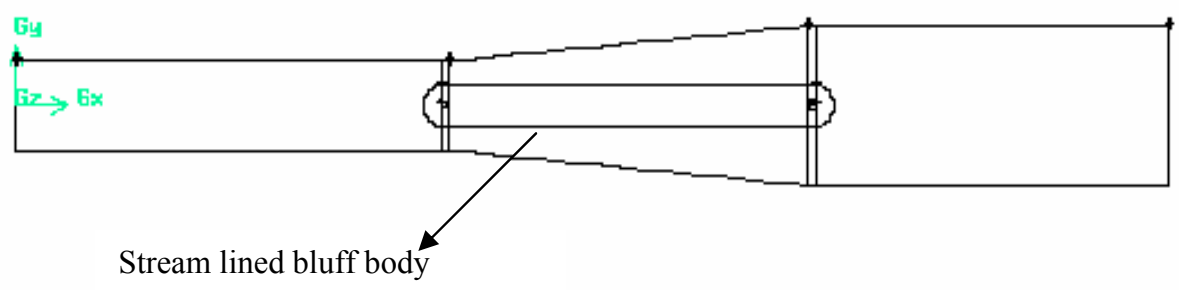

Figure 3: Annular diffuser with stream lined bluff body with circular struts.

\subsection{Annular diffuser with stream lined centre body with circular struts (Case B)}

Since the sharp ends are not favorable for the flow, stream lined centre body has been used. This model is used for the validation purpose also. From the velocity vector plots we can observe the magnitude and direction of velocity in the flow field. The color code and the corresponding velocity magnitude are given in the left side margin. In a plane along the struts, velocity vectors close to the conical wall are distorted because of the boundary layer development and the struts wakes. From Fig.5 we can observe velocity vector variations in struts plane and at different planes including the plane along the struts 
respectively. Magnitude of velocity in the near wall regions is less because of the boundary layer development and in the core regions velocity magnitude is high.

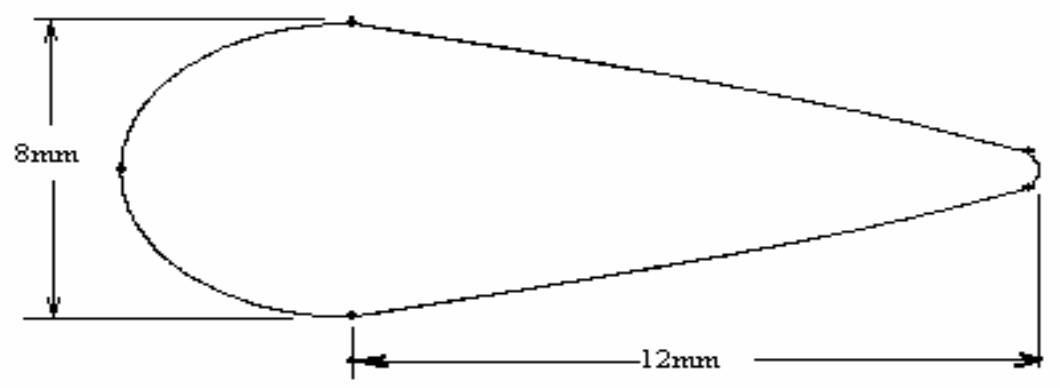

Figure 4: Cross section of the aerofoil shaped strut.

Struts and their wakes reduce the flow area in the region close to the struts. As the flow develops the velocity reduces due to diffusion. The effect of struts and its wakes at different planes along the axial direction is shown in Fig.6. The wake effect is observed behind the struts. In the stream wise direction, the boundary layer thickness increases because of adverse pressure gradient and also the velocity gradient near the wall. The boundary layer characteristics on both the walls are different. Hence, the peak value of velocity may not occur at the centre line region. The magnitude of maximum velocity value shifts from the wall region due to boundary layer. From the inlet to the outlet of the diffuser mean velocity reduces and this reduction in velocity is converted into pressure rise.

Figure 7 shows the variation of static pressure in a plane along the struts. In the plane of the struts static pressure reduces to a very low value. As the area ratio increases, the static pressure also increases due to diffusion.

Turbulence intensity is high near the region of the struts (Fig.8) because of production of high kinetic energy along the axial plane of the struts. Turbulent intensity is higher in the region where the fluctuations are large. From struts, wakes are produced, and these wakes diffuse to the surrounding region towards the outlet region of the diffuser. Figure 9 shows the effect of struts on the turbulent kinetic energy. As flow proceeds from the inlet of the diffuser, the production of kinetic energy at the wall decreases, whereas there is an increase in the production of kinetic energy per unit mass in the core region of the diffuser. Turbulent intensities first build up at locations where the velocity gradient is high. Turbulent kinetic energy possessed by the wake is more in the initial stations and it decreases with increase in area ratio. Turbulent intensity is increasing towards the outlet portion of the diffuser, where shear stress gradient comes into prominence and the maximum values of turbulent kinetic energy shifts away from the wall.

\subsection{Annular diffuser with stream lined bluff body without struts (Case B)}

The presence of struts in annular diffuser causes a flow blockage and reduction of diffusion. The overall performance of the diffuser is highly influenced by the diffuser inlet blockage. The inlet flow area to the diffuser is increased in the case of bluff body without struts.

Wakes of the struts, which reduces diffusion and increases the dissipation effects is also absent in this case. Here the flow is only affected by the boundary layer development at the inlet of the diffuser. As the flow proceeds into the diffuser, thick boundary layer nearer to the walls increases the velocity gradient and in the core region the flow velocity magnitude will be more compared to the wall region.

The contour plot of mean axial velocity for the model without struts shows (Fig.10) a high gradient of velocity close to the conical wall and bluff body nearer to the exit region of the diffuser which is due to the boundary layer effect in the adverse pressure gradient. Moreover turbulent intensity (Fig.11) 
increases at the exit of the diffuser near the wall regions due to the increased shear stresses. Skin friction coefficient increases towards the exit region of the diffuser.

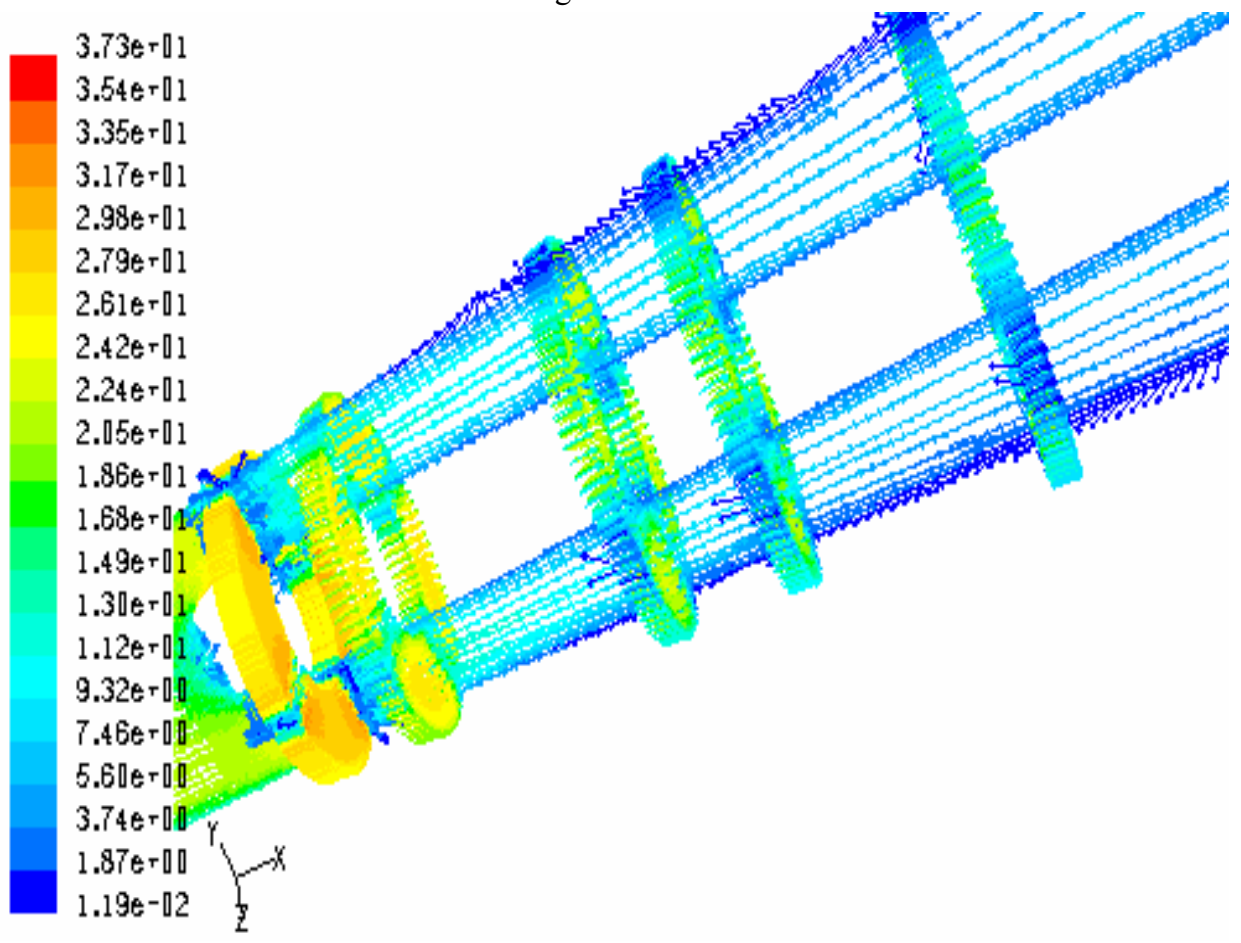

Figure 5: Velocity vectors in $\mathrm{m} / \mathrm{s}$ along the plane of the struts and along different planes

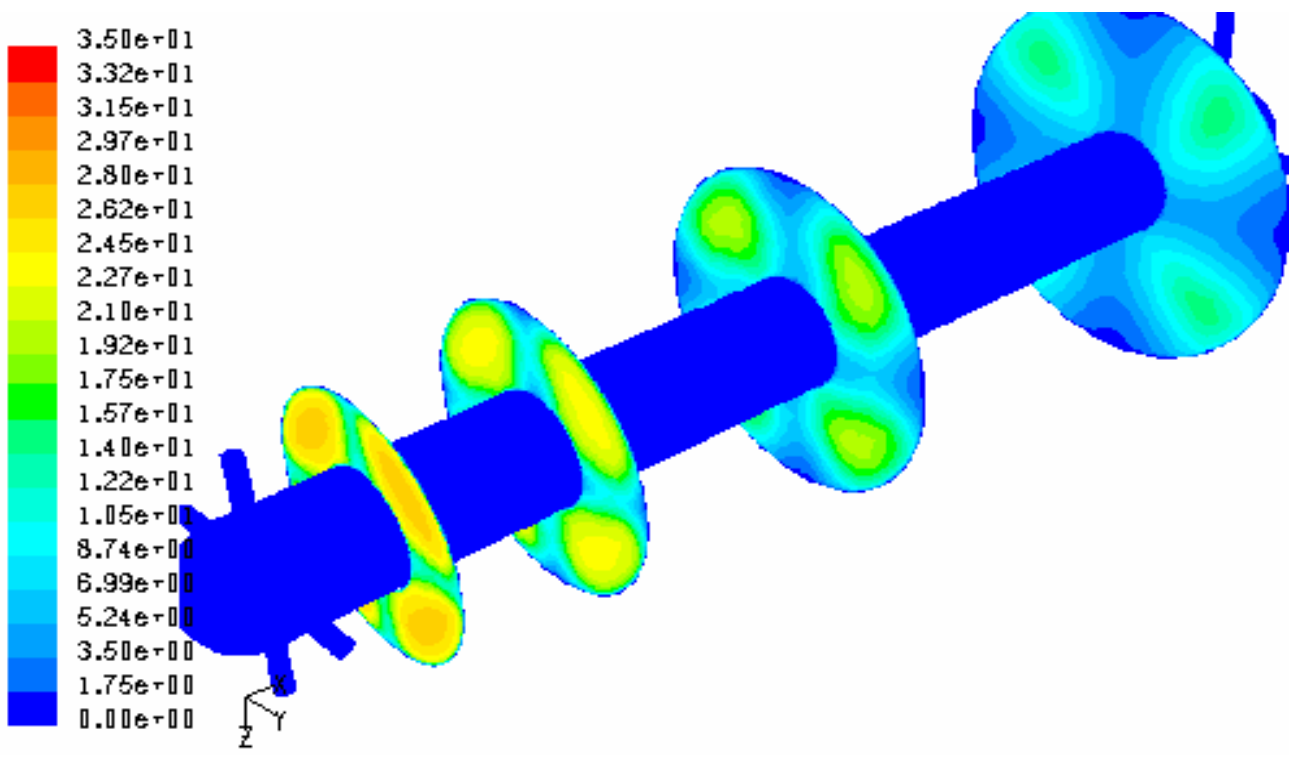

Figure 6: Velocity magnitude $(\mathrm{m} / \mathrm{s})$ contours at different planes

The comparison of effectiveness of the diffusers of different geometries is shown in Fig.12. Effectiveness of the annular diffuser increases by $10 \%$ by the removal of the struts. Diffuser without 
struts reduces the total pressure loss across the model by $56 \%$ compared to a diffuser with struts. This shows that in the design one must provide, minimum blockage due to struts.

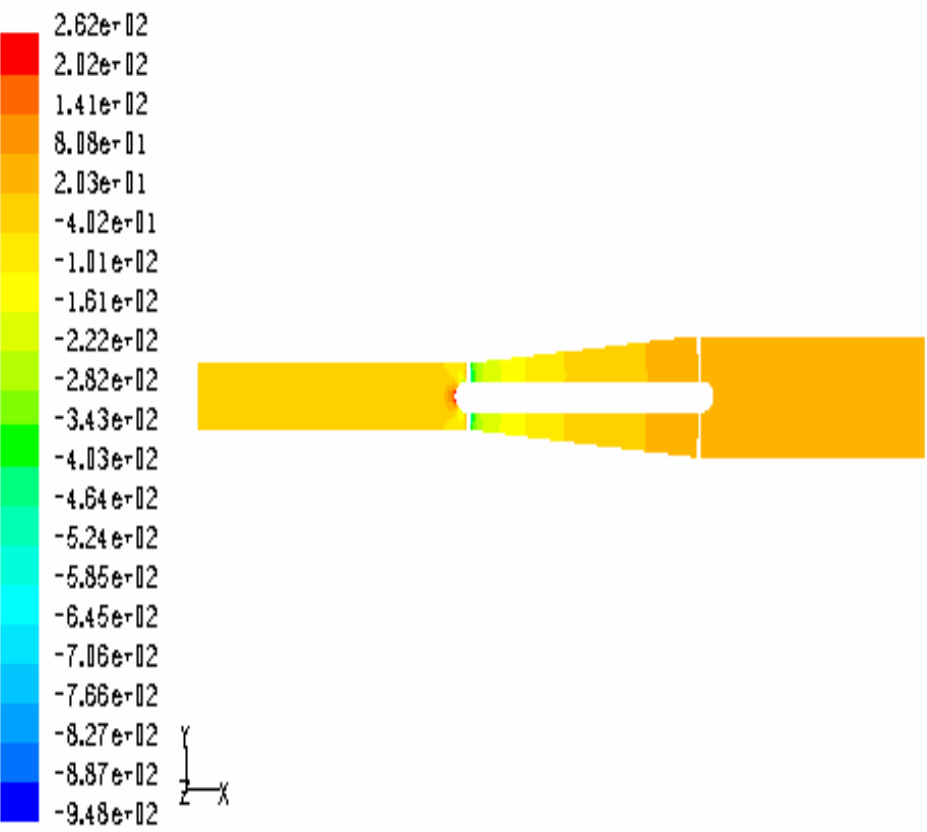

Figure 7: Static pressure $(\mathrm{Pa})$ contours in a plane along struts

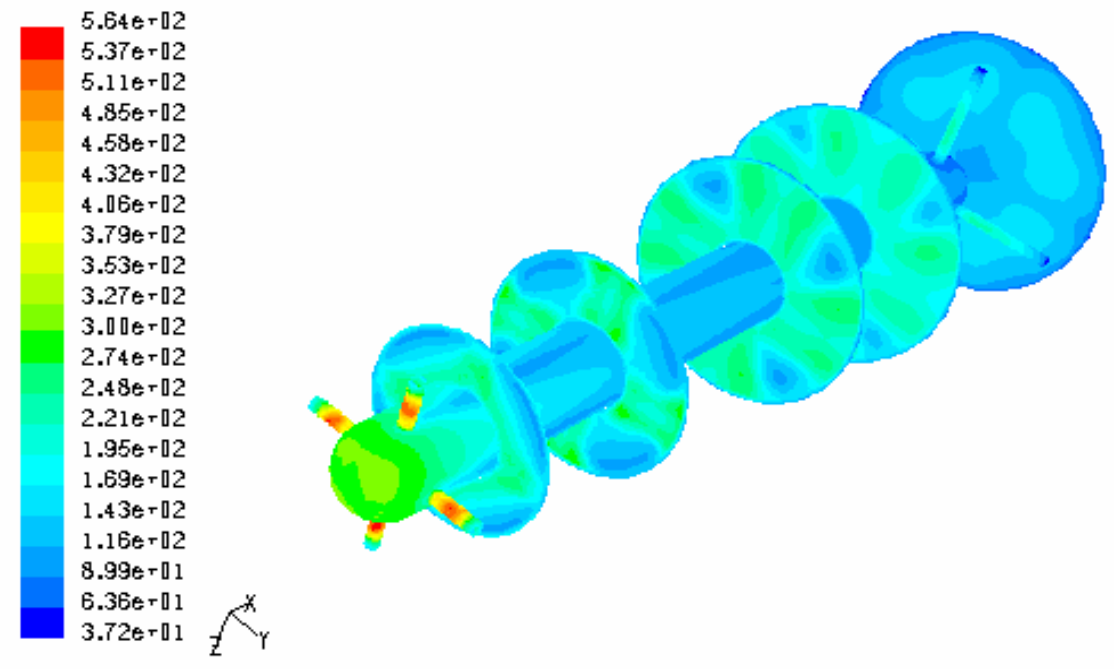

Figure 8: Turbulent intensity (\%) contours at different planes

\subsection{Annular diffuser with stream lined bluff body with aerofoil shaped struts (Case C)}

Having analyzed the flow with and without strut it is now proposed to evaluate the shape of the strut in the flow development. Aerofoil shaped struts allows a stream lined flow over it, which reduces the wake formation from the struts. The wall boundary layers often extend across most of the strut span and produce a horseshoe vortex at wall regions. These vortices then lead to secondary flow effects, which dominate the whole of the flow field. Aerofoil shaped struts used has the same blockage as that of the circular struts. Because of the streamlined flow over the struts, wake effects produced by the 
struts will be less. Compared to the circular struts (Case A), the turbulence created by the aerofoil struts is quite less. So only the boundary layer effect due to the adverse pressure gradient affects the flow.

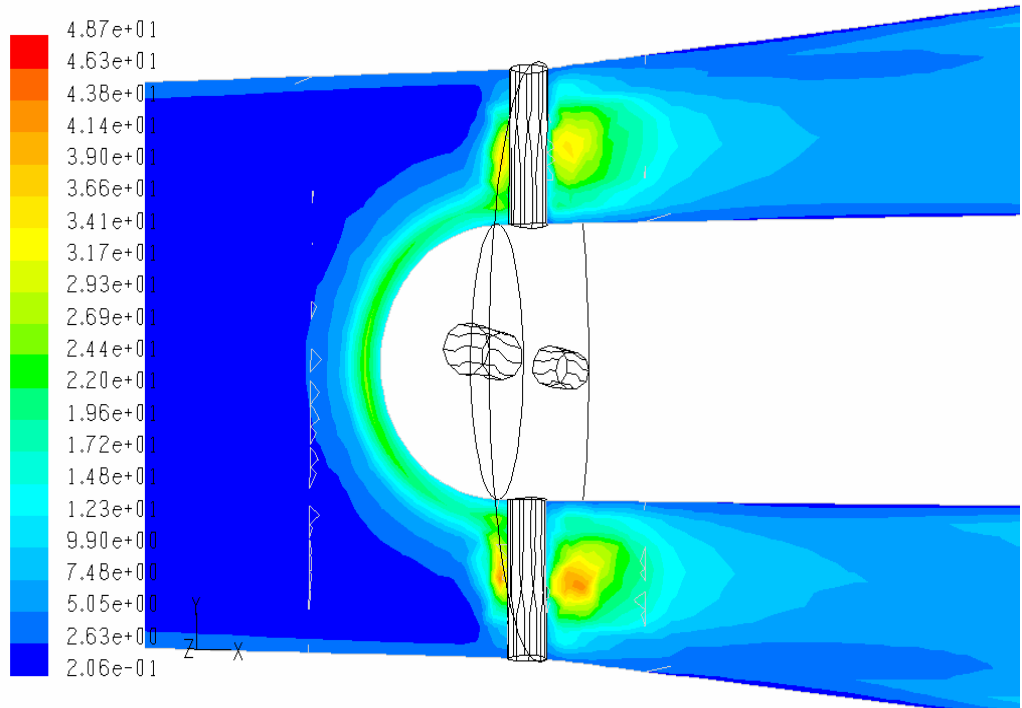

Figure 9: Turbulent kinetic energy $\left(\mathrm{m}^{2} / \mathrm{s}^{2}\right)$ at the inlet section of the diffuser

The velocity vector plot (Fig.13) along the struts plane shows that the distortion of the axial velocity vector, which is produced by the struts wake is less compared to the circular struts model. Pressure recovery is improved by using aerofoil shaped struts. Improvement in the effectiveness of the diffuser is about 3\%. Reduction in total pressure loss across the model compared to Case B is $26.5 \%$.

\section{Validation}

For the validation of the numerical simulation a uniform flow of air at an average velocity of about 20 $\mathrm{m} / \mathrm{s}$ at the inlet of the annular diffuser has been considered. Model in Case B is used for the validation purpose. The inlet Reynolds number based on the mean inlet velocity and diffuser inlet radius is calculated as $1.465 \times 10^{5}$. Thus the flow is turbulent at the inlet and it is developing under adverse pressure gradient in the diffuser. The entire flow domain is assumed to be incompressible.

The comparison of the experimental values with the standard k- $\varepsilon$ model predictions are presented and discussed in the following order; mean velocity variations in radial directions at different axial locations of annular diffuser. The experimental values are given by symbols and theoretical predictions are denoted by solid lines.

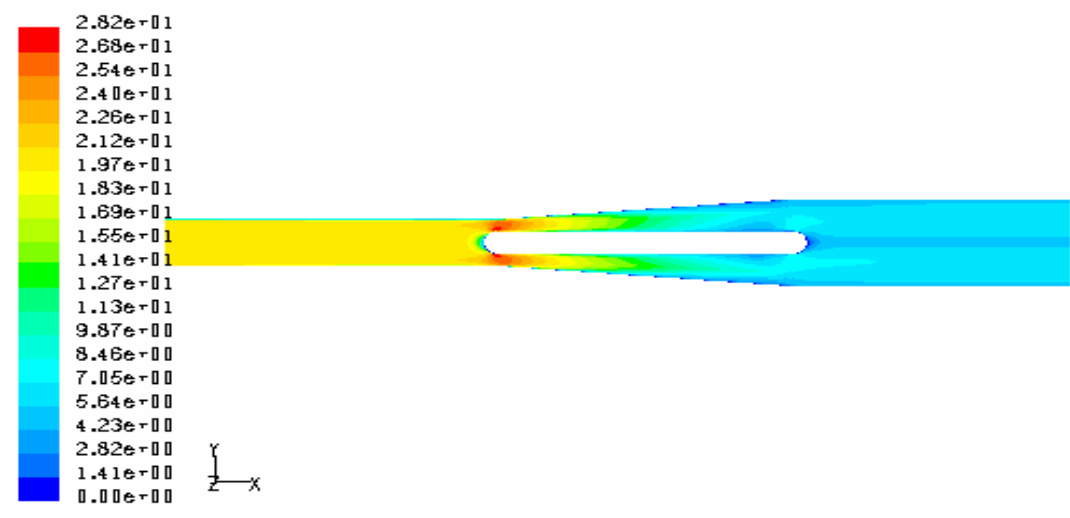

Figure 10: Axial velocity $(\mathrm{m} / \mathrm{s})$ contour at the mid plane 


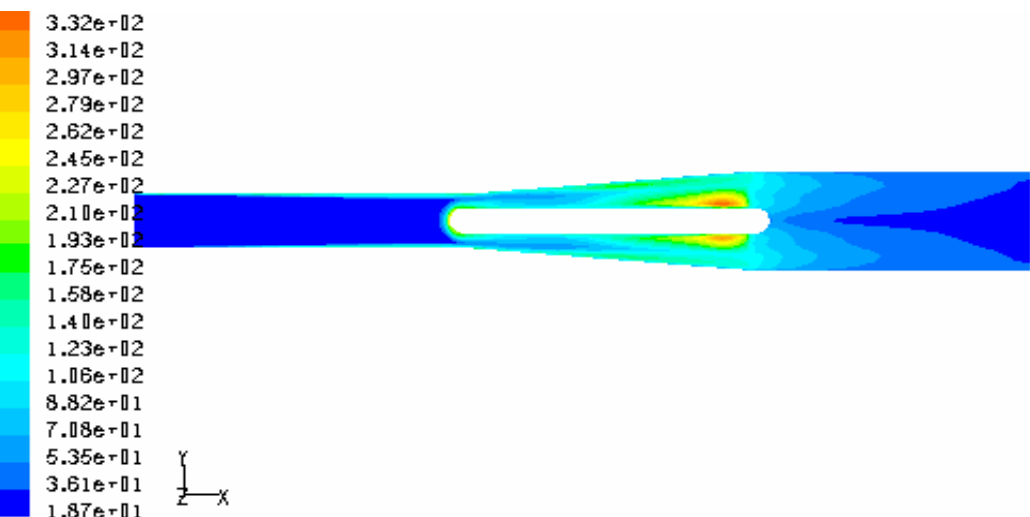

Figure 11: Turbulent intensity (\%) along the mid plane

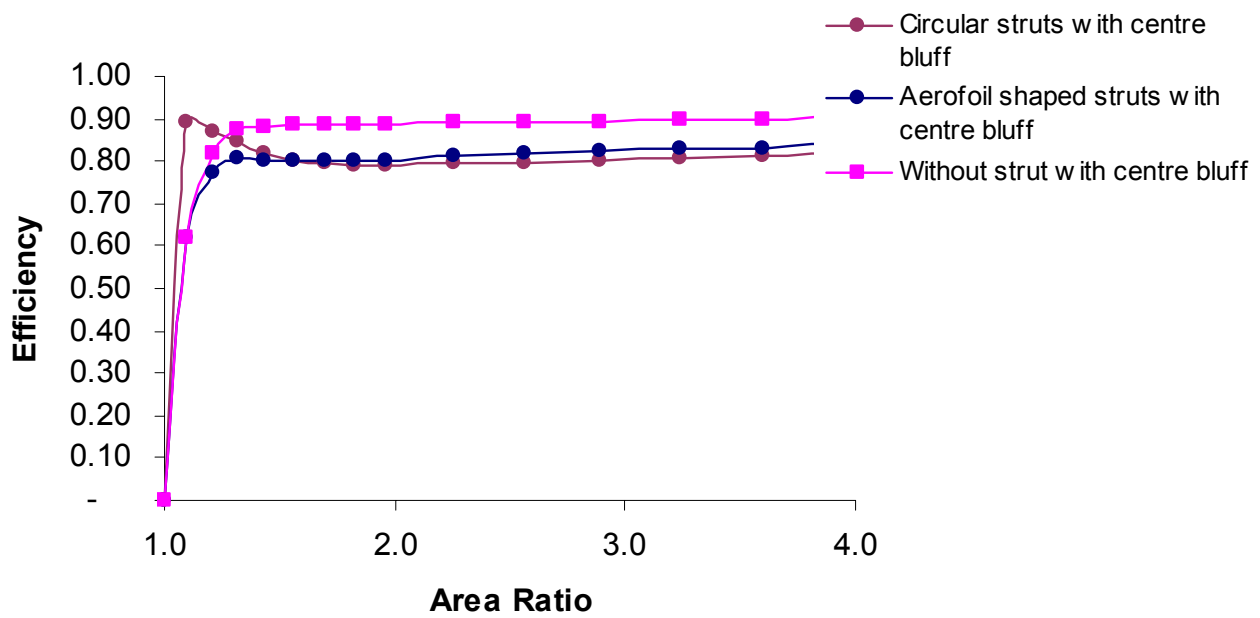

Figure 12: Comparison of effectiveness of diffusers of different geometry

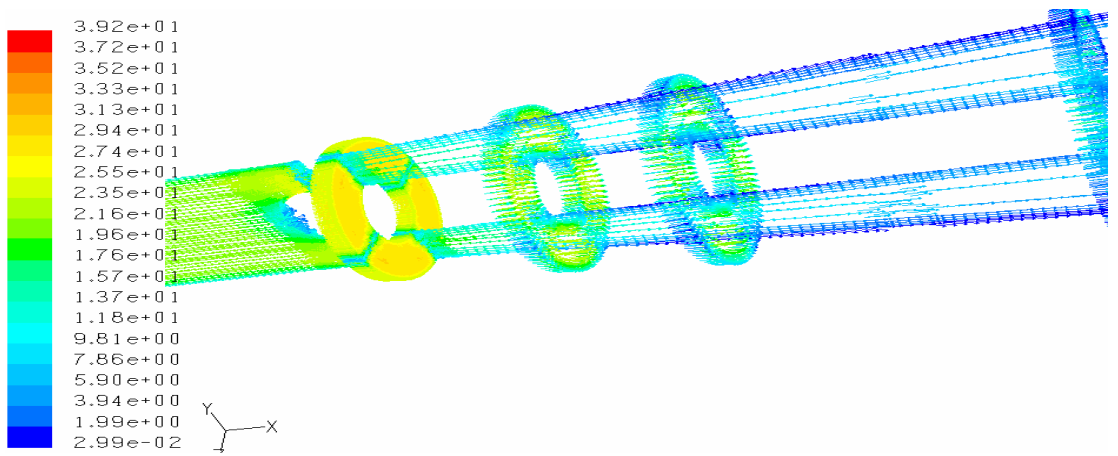

Figure 13: Velocity vectors $(\mathrm{m} / \mathrm{s})$ along the struts plane and in different planes

\section{Axial velocity}

Figure 14 (1-9) shows the radial distribution of axial velocity at nine axial stations of the diffuser. Experimental values obtained from five hole probe and hot wire anemometer also have been superimposed on the figures. The flow decelerates from the inlet of the diffuser to the outlet portion of 
the diffuser as can be seen from the $U_{a v}$ values printed on the figures. The maximum error between the measurement and the prediction at the various stations has also been printed to show the deviation.

From the inlet velocity profile, at station ' 1 ' it is clear that the inlet flow consists of a central core region with almost constant velocity of $20 \mathrm{~m} / \mathrm{s}$ and the flow distortion is only due to the boundary layer development near the wall. At the measuring station ' 2 ', just after the struts, the predicted flow field behind the strut is shown in Fig. 15. The plane which is shown in the figure is $5 \mathrm{~mm}$ below the conical wall. When fluid flows over the struts at the point of flow separation from the wall of the strut fluid accelerated and a recirculation zone is formed just after the strut. At this region velocity is reduced to a very low value and the turbulence due to this recirculation is high. The separated flow from the strut moves away from the plane of the strut and the wakes produced by the recirculation moves along the plane of the struts. These vortices produced across the struts span and will lead to secondary flow effect in the flow field along the plane of the struts. Measurements at station are affected by the wakes produced by the struts. Struts have a strong effect on the flow development since large regions behind the strut are occupied by their wakes. These trends are due to the effect of area ratio and the adverse pressure gradient in the wake development. So a lot of unsteady flow phenomena take place at station ' 2 '.

We can see the $100 \%$ deviation between the experimental and predicted axial velocity plots at station ' 2 ', because of the above mentioned unsteadiness in the flow. Since we used a steady flow calculations in the solution probably it was not able to capture the unsteadiness in the flow at station 2.

At measuring station ' 3 ' it is found that the flow velocity has increased compared to station ' 2 '. After the recirculation in station ' 2 ' the fluid in that zone also moves along with the fluid main stream and the effect of wakes starts disappearing. So the velocity at station ' 3 ' is increased compared to station'2'.

From station ' 4 ' to station 8 , all the plots shows the same trend of velocity distribution, magnitude of velocity decreases with increase in area ratio of the diffuser. The magnitude of velocity near the outer wall is less compared to the inner wall. It is due to the fact that boundary layer thickness at the outer wall is larger than that at the inner wall.

Station ' 9 ' is in the outlet pipe; near the wall region velocity is less because of boundary layer. In the centre region of the pipe also the velocity reduces, where fluid come out of the diffuser from the struts and bluff body region will produce a low velocity magnitude region in front of the bluff body. Figure 14 illustrate that except in the measuring station ' 2 ' experimental data are in good agreement with predicted mean velocities, within an experimental error of 5\%. Kjelgaard (1988) after comparing with Laser Doppler measurements recommended five hole probe in low gradient flows so as to capture the values with less than 5 percent error.

\section{Conclusions}

The $k$ - $\varepsilon$ model is found to be a satisfactory physical model to give good predictions for various flow characteristics of an annular diffuser. Static pressure rise is well predicted by the numerical model which has close agreement with experiment. The diffusion in the diffuser with struts is interrupted by the reduction of the flow area due to the struts and their wakes. The pressure loss is significantly increased by the presence of struts. Pressure recovery development in the diffuser without struts is higher than the pressure recovery in the diffuser with struts. The effectiveness of the diffuser with aerofoil shaped struts is 3\% more than the diffuser with circular struts even though the blockages are same. Thus struts play an influential role in the diffuser performance. The present study indicates that the prediction procedure used in the paper can be used with confidence in the development of prediffusers for the marine gas turbine combustors. 


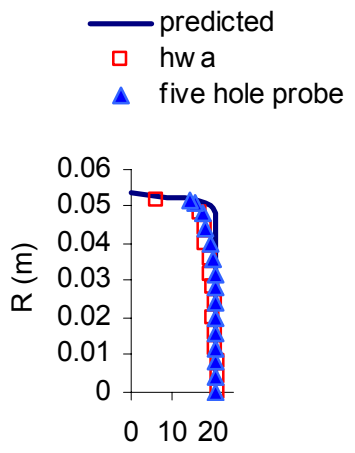

Uaxial $(\mathrm{m} / \mathrm{s})$

1. $U a v=19.11 \mathrm{~m} / \mathrm{s}$ ( $2 \%$ error)
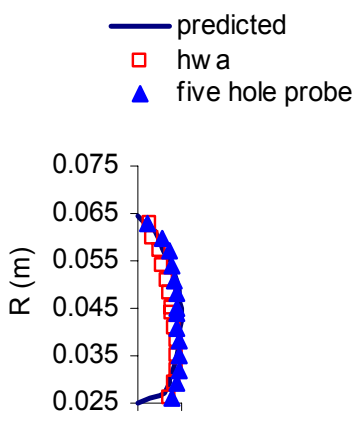

010

Uaxial $(\mathrm{m} / \mathrm{s})$

4. Uav $=7.03 \mathrm{~m} / \mathrm{s}$

(5\%error)
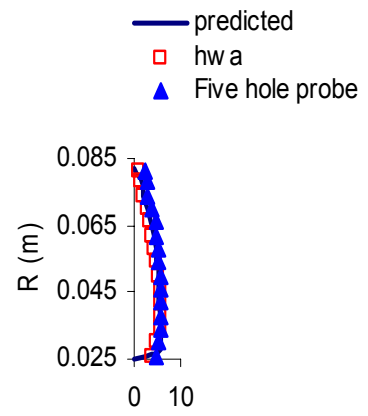

Uaxial $(\mathrm{m} / \mathrm{s})$

7. Uav $=4.18 \mathrm{~m} / \mathrm{s}$ (3\% error)

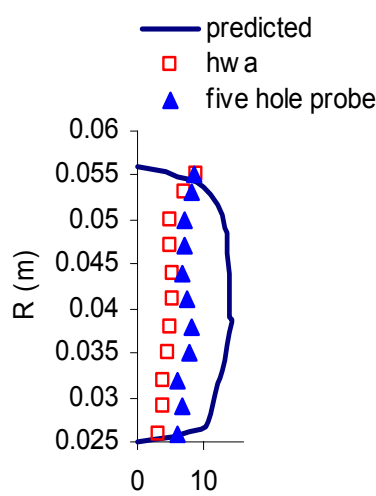

Uaxial $(\mathrm{m} / \mathrm{s})$

2. Uav $=4.82 \mathrm{~m} / \mathrm{s}$
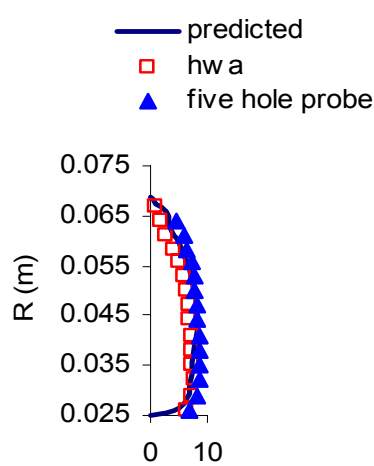

5. Uav $=5.78 \mathrm{~m} / \mathrm{s}$

(4\% error)
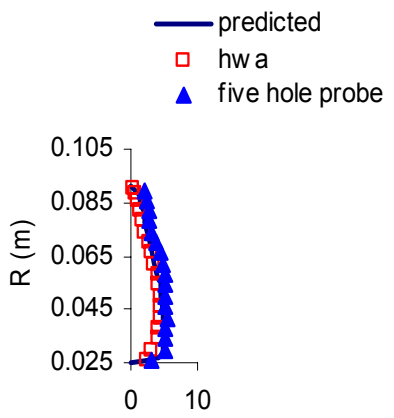

Uaxial $(\mathrm{m} / \mathrm{s})$

8. Uav $=3.15 \mathrm{~m} / \mathrm{s}$ ( $2 \%$ error)
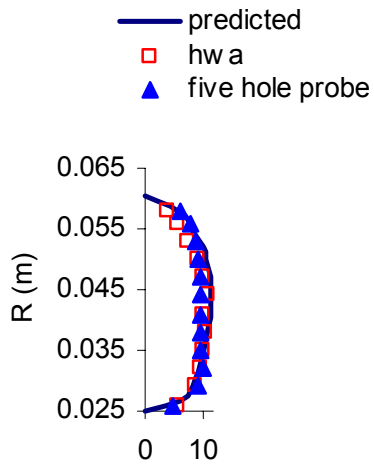

Uaxial $(\mathrm{m} / \mathrm{s})$

3. Uav $=8.75 \mathrm{~m} / \mathrm{s}$

(4\% error)

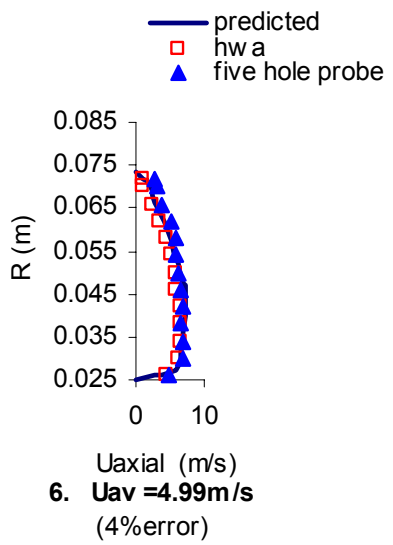

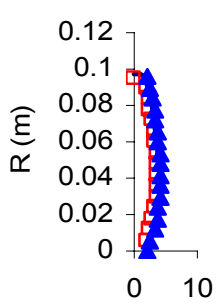

Uaxial $(\mathrm{m} / \mathrm{s})$ 9 Uav $=0.92 \mathrm{~m} / \mathrm{s}$ (1\% error)

Figure 14: Radial distribution of axial velocity Comparison between experiments and predictions 


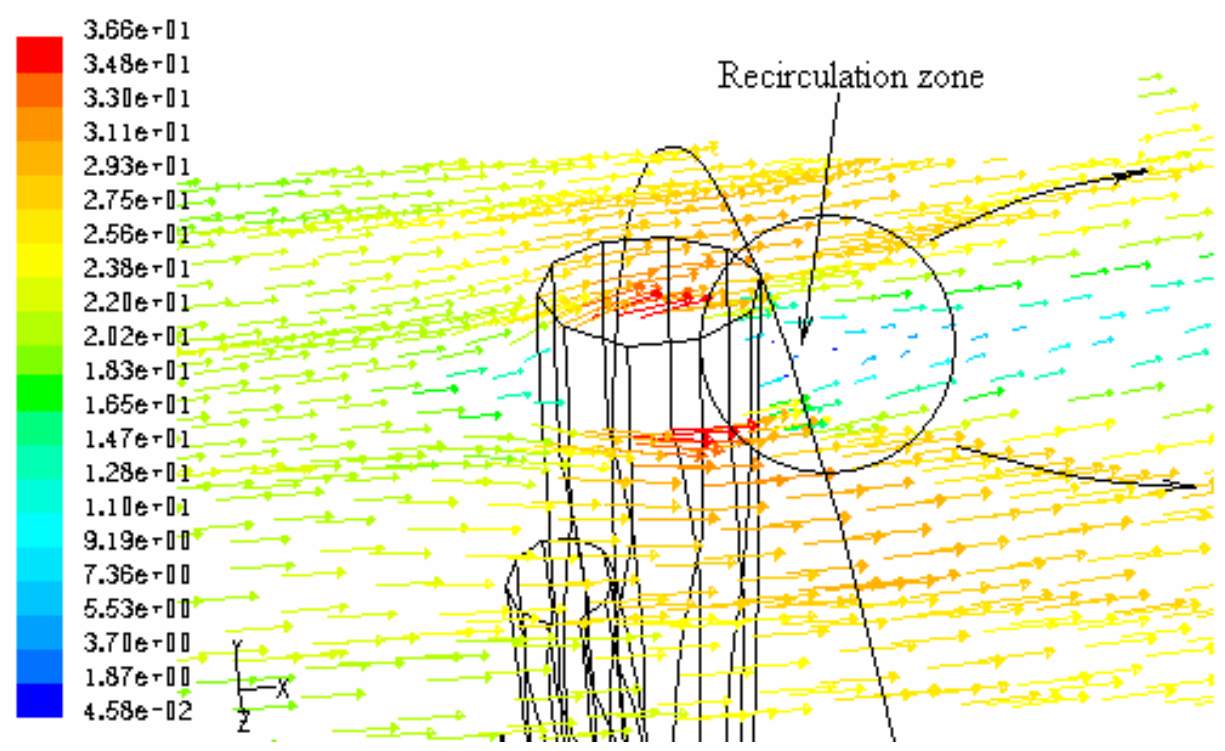

Figure 15: Velocity vectors just behind the strut, at station '2'

\section{References}

Brunn. H. H. (1995): Hot-Wire Anemometry:Principles and Signal Analysis, Oxford University Press Inc., New york.

Fric. T.F, R. Villarreal, R. O. Auer, M. L. James, D. Ozgur and T. K. Staley (1996): Vortex Shedding from Struts in an Annular Exhaust Diffuser, GE Research and Development Center, Technical Information Series, 96CRD078

Ganesan, V. (1980): Flow and boundary layer development in straight core annular diffusers, International Journal of Engineering and Science, Vol.18, pp. 287-304

Hobson. D. E. and M. Jedwad (1990): Investigations of the Effect of Eccentricity on the Unsteady Fluid Forces on the Centre body of an Annular Diffuser, Journal of Fluids and Structures, Vol. 4, pp. 155-169

Kjelgaard. S. O. (1988): Theoretical derivation and Calibration Technique of a Hemispherical -tipped Five-hole Probe, NASA TM-4047, pp. 199-203

Roach. P. E. and J. T. Turner (1985): Secondary Loss Generation by Gas Turbine Support Struts, International Journal of Heat and fluid Flow, Vol.6, pp.79-88.

Shuja. S. Z. and M. A. Habib (1995): Fluid Flow and Heat transfer Characteristics in Axisymmetric Annular Diffusers, Computers and Fluids, Vol. 25, pp.133-150.

Shyy. W. (1985): A Numerical Study of Annular Dump Diffuser Flows, Computer Methods in Applied Mechanics and engineering Vol. 25, pp.47-65

Stefano Ubertini and Uberto Desideri (July, 2000): Experimental Performance Analysis of an Annular Diffuser With and Without Struts, Experimental Thermal and Fluid Science, Vol. 22, pp.183-195.

Stefano Ubertini and Uberto Desideri (March, 2000): Flow Development and Turbulence Length Scales within an Annular Gas Turbine Exhaust Diffuser, Experimental Thermal and Fluid Science, Vol. 22, pp.55-70. 